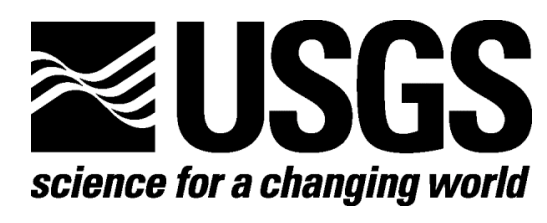

\title{
Side-scan Sonar Imaging of the Colorado River, Grand Canyon
}

By Roberto Anima, ${ }^{1}$ Florence L. Wong, ${ }^{1}$ David Hogg, ${ }^{1}$ and Peter Galanis ${ }^{1}$

Open-File Report 2007-1216

2007

U.S. Department of the Interior

U.S. Geological Survey

${ }^{1}$ Menlo Park, Calif. 


\title{
U.S. Department of the Interior DIRK KEMPTHORNE, Secretary
}

\section{U.S. Geological Survey \\ Mark D. Myers, Director}

\author{
U.S. Geological Survey, Reston, Virginia 2007
}

For product and ordering information:

World Wide Web: http://www.usgs.gov/pubprod

Telephone: 1-888-ASK-USGS

For more information on the USGS-the Federal source for science about the Earth, its natural and living resources, natural hazards, and the environment:

World Wide Web: http://www.usgs.gov

Telephone: 1-888-ASK-USGS

Suggested citation:

Anima, Roberto, Wong, Florence L., Hogg, David, and Galanis, Peter, 2007, Side-scan sonar imaging of theColorado River, Grand Canyon: U.S. GeologicalSurvey Open-File Report 2007-1087, 15 p. [http://pubs.usgs.gov/of/2007/1216/].

Any use of trade, product, or firm names is for descriptive purposes only and does not imply endorsement by the U.S. Government.

Although this report is in the public domain, permission must be secured from the individual copyright owners to reproduce any copyrighted material contained within this report. 


\section{Abstract}

This paper presents data collection methods and side-scan sonar data collected along the Colorado River in Grand Canyon in August and September of 2000. The purpose of the data collection effort was to image the distribution of sand between Glen Canyon Dam and river mile 87.4 before and after the 31,600 cfs flow of September 6-8. The side-scan sonar imaging focused on pools between rapids but included smaller rapids where possible.

\section{Introduction}

Side-scan sonar data was collected within the Colorado River as part of a multifaceted scientific effort under the Grand Canyon Monitoring and Research Center (GCMRC) to provide information on the long-term changes of the river under the Glen Canyon Dam Adaptive Management Program (AMP). This program is designed to help the federal government understand the relationship between dam operations and the health of the river system so that it can meet its resource management obligations under the 1992 Grand Canyon Protection Act, the 1995 Glen Canyon Dam Environmental Impact Statement, and the 1996 Record of Decision.

Side-scan sonar has proven to be a useful tool in the marine environment to investigate oil and gas pipeline locations, shipwrecks, rock outcrops, and sediment distribution. An earlier attempt to collect side-scan sonar data along the Colorado River in Grand Canyon was undertaken in by Wilson in 1984 (1998, personal communication) who used onshore reference points on aerial photography as navigation controls for the side-scan sonar. Since this work, the advent of the Global Positioning System (GPS) has increased the feasibility and efficiency of side-scan sonar for the Grand Canyon

During this study the side-scan data bracketed the 31,600 cfs experimental flow of September 6-8, that followed the Low Steady Summer Flow (LSSF), (http://www.usgs.gov/newsroom/article_pf.asp?ID=478), with the first survey conducted August 28 to September 5, 2000 (R3-00-GC) and the second conducted September 10-18, 2000 (R4-00-GC). Each survey proceeded from Glen Canyon Dam and ended at Diamond Creek, and included the same reaches of the corridor (Figure 1). Interest and time allowed for focusing our resources on the Tailwaters section (Glenn Canyon Dam to Lees Ferry, mile -15 to mile 0 ) to the Kaibab Bridge (mile 88.0). Distances and references along the river are in miles using the Grand Canyon Monitoring and Research Center's web site. (http://www.gcmrc.gov/website/fist/viewer), and the Colorado River in Grand Canyon Guide (Stevens, 1983). Data collected during both surveys cover most of the pools that occur between rapids (Figure 1). Table 1 shows the reaches covered and the images included in this report. The accompanying DVD contains the reaches covered in this report.

\section{Purpose and Scope}

The purposes of this manuscript are to: 1) present the methods used in the data collection, 2) present some limited data analysis showing how well the different bed material types can be identified in the images, and 3) deliver the images for potential future analysis by others. 


\section{Methods}

A 22-foot inflatable river raft (snout rig) was used to collect the data (Figure 2). A Klein $500 \mathrm{kHz}$ side-scan sonar tow fish was used to conduct the surveys above the Little Colorado River (LCR). The pre-LSSF (R3) survey found the Little Colorado discharging a large quantity of fine-grained sediment that attenuated the outgoing signal so much that operations were stopped. The survey switched to a $100 \mathrm{kHz}$ tow fish for reaches between the LCR and Diamond Creek. The next survey (R4) used the Klein $500 \mathrm{kHz}$ tow fish for the entire survey.

Side-scan sonar images were processed with the USGS Mini Image Processing system (MIPS) http://terraweb.we.usgs.gov/software/mips/, a set of software tools that are used to convert rectangular blocks of raw data to geo-referenced images in UTM 11 coordinates in MPS "raw" or bil (band interleaved by line) format. The processed images have pixel values of 0 to 255, indicating a range of sonar reflectance from low to high. The resolution of the side-scan sonar images is 0.2 meters per pixel. The images were converted to TIFF format for use with Adobe Photoshop and Adobe Illustrator software.

Side-scan sonar TIFF images were imported into Adobe Photoshop where pixel values were inverted so that bedrock and boulders, which have high sonar reflectance, appear as dark reflectors, whereas sand and gravel, which have low sonar reflectance, appear as various shades of white to dark gray. Because of intermittent GPS coverage, most images required further manual registration.

\section{Navigation}

Navigation was attained in two ways. First, a Global Positioning System (GPS) collected Latitude and Longitude data using two GPS units. The antenna was mounted on a stationary frame that was located within 3.5 meters above the tow fish. The data were collected and stored on hard disk and optical drive for later processing. The orientation and steepness of the canyon walls, however, limited reception of satellite signals and in some cases introduced errors, perhaps due to reflection off the canyon walls.

The second method used aerial photographs as a backup to the GPS. Ortho-rectified aerial photograph coverage for the entire river allowed us to correlate features visible along the shoreline with the photographs. One person matched features along the shore that were visible on the aerial photographs and simultaneously marked the aerial photograph. The mark was called to the side-scan sonar operator who placed a time mark on the side-scan sonar record, and marked a GPS fix on the hand held units. The aerial photograph data proved invaluable where the GPS signal was either lost or reflected on the canyon walls.

The side-scan sonar images were given number designations, i.e., r4-00-blcr1a. Each designation includes the survey number $(\mathrm{r} 3, \mathrm{r} 4)$ and the year $(-00-)$. The letters and numbers that follow represent the area covered, (i.e., blcr, below the Little Colorado River, and zc, Zoraster Canyon to Cremation). The number shows the line number run in the area. The brackets drawn on each image indicate where along the track line the pre-and postsurvey lines match up. 
Table 1 showing letter designations for each area surveyed. River miles are commonly used along the Colorado River as reference points and are used here.

\begin{tabular}{|c|c|c|}
\hline River Mile & Pre-flow Data & Post-flow Data \\
\hline \multicolumn{3}{|l|}{$\begin{array}{l}\text { TW Tailwaters (0 to }-15 \\
\text { miles) }\end{array}$} \\
\hline Mile -15.7 to -14.5 & $\begin{array}{l}\text { r3-00-tw1d } \\
\text { r3-00-tw1c }\end{array}$ & $\begin{array}{l}\text { r4-00-tw1c_A } \\
\text { r4-00-tw1c_B }\end{array}$ \\
\hline Mile -14.9 to Mile -13.5 & r3-00-tw1d & r4-00-tw2b \\
\hline Mile -13.0 to Mile -10 & r3-00-tw2a & $\begin{array}{l}\text { r4-00-tw2b_A } \\
\text { r4-00-tw3a }\end{array}$ \\
\hline Mile -10.0 to Mile -6.0 & $\begin{array}{l}\text { r3-00-tw3a } \\
\text { r3-00-tw3a_B } \\
\text { r3-00-tw4a }\end{array}$ & $\begin{array}{l}\text { r400tw3a } \\
\text { r400twr4a_A2 } \\
\text { r400tw4a_B }\end{array}$ \\
\hline Mile -6.0 to Mile 0 & $\begin{array}{l}\text { r3-00-tw4a } \\
\text { r3-00-tw5a_A \& B }\end{array}$ & $\begin{array}{l}\text { r4-00-tw5a_B } \\
\text { r4-00-5a_C } \\
\text { r4-00-tw5b_A \& B }\end{array}$ \\
\hline $\begin{array}{l}\text { BP Paria River to } \\
\text { Cathedral Wash ( } 1 \text { to } 3 \\
\text { miles) }\end{array}$ & r3-00-bp1a & r4-00-bp1a \\
\hline $\begin{array}{l}\text { BCH Below Cathedral } \\
\text { Wash (Miles } 3.5 \text { to } 7.9 \text { ) }\end{array}$ & $\begin{array}{l}\text { r3-00-bch1A } \\
\text { r3-00-bch1B_B }\end{array}$ & $\begin{array}{l}\text { r4-00-bch1_A } \\
\text { r4-00-bch1B-B }\end{array}$ \\
\hline $\begin{array}{l}\text { Between } 6 \text { Mile Wash } \\
\text { and below Mile } 6\end{array}$ & r3-00-bch1B_C & r4-00-bch1_B-C \\
\hline $\begin{array}{l}\text { TS - Tiger Wash to } \\
\text { Shinumo Wash (Miles } \\
\text { 26to Mile 29.2) }\end{array}$ & r3-00-ts1a & $\begin{array}{l}\text { r4-00-ts1a_A } \\
\text { r4-00-ts1a_B }\end{array}$ \\
\hline $\begin{array}{l}\text { SSC - Shinumo Rapid to } \\
\text { South Canyon (Miles } \\
29.4 \text { to } 31.6 \text { ) }\end{array}$ & $\begin{array}{l}\text { r3-00-ssc1a } \\
\text { r3-00-ssc2 }\end{array}$ & $\begin{array}{l}\text { r4-00-ssc1a } \\
\text { r4-00-ssc2a } \\
\text { r4-00-ssc2b } \\
\text { r4-00-ssc2c } \\
\text { r4-00-ssc2e } \\
\text { r4-00-ssc2b_2 }\end{array}$ \\
\hline $\begin{array}{l}\text { TP }-36 \text { Mile Rapid to } \\
\text { President Harding Rapid } \\
\text { (Miles } 36 \text { to } 38 \text { ) }\end{array}$ & r3-00-tp1a & r4-00-tp1a_A \\
\hline $\begin{array}{l}\text { PHS - President } \\
\text { Harding to Saddle } \\
\text { Canyon (Miles } 44.8 \text { to } \\
46.4 \text { ) }\end{array}$ & r3-00-phs2-A \& B & r4-00-phs1c_B \\
\hline $\begin{array}{l}\text { SN - Saddle Canyon to } \\
\text { Nankoweap Rapid } \\
\text { (Miles } 47.5 \text { to } 50.6)\end{array}$ & r3-00-sn2_A & r4-00-sn1a_A \\
\hline $\begin{array}{l}\text { SLC - Sixty Mile Rapid } \\
\text { to the Little Colorado } \\
\text { (Miles } 60.6 \text { to } 61.7 \text { ) }\end{array}$ & r3-00-slc1_a & r4-00-slc1_a \\
\hline $\begin{array}{l}\text { BLCR - Below the } \\
\text { Little Colorado to } \\
\text { Tanner Rapid (Miles } 62 \\
\text { to } 68.5 \text { ) }\end{array}$ & $\begin{array}{l}\text { r3-00-blcr 2a, 3a, 4a } \\
\text { r3-00-blcr 5a_A }\end{array}$ & $\begin{array}{l}\text { r4-00-blcr 1a } \\
\text { r4-00-blcr 2A } \\
\text { r4-00-blcr2a_A }\end{array}$ \\
\hline Mile 63.8 to Mile 68.9 & $\begin{array}{l}\text { r3-00-blcr5a_B } \\
\text { r3-00-blcr6a_B } \\
\text { r3-00-blcr 6a_A }\end{array}$ & $\begin{array}{l}\text { r4-00-blcr2_B } \\
\text { upper part of r4-00-blcr3a } \\
\text { lower section of r4-00-blcr3a } \\
\text { upper r4-00-blcr3b }\end{array}$ \\
\hline $\begin{array}{l}Z C-\text { Zoraster Rapid to } \\
\text { Bright Angle Rapid } \\
\text { (Miles } 86.1 \text { to } 88 \text { ) }\end{array}$ & $\begin{array}{l}\text { r3-00-zc2a_A } \\
\text { r3-00-zc2a_B }\end{array}$ & r4-00-zc1a \\
\hline
\end{tabular}




\section{Features shown on images}

The accompanying DVD contains files with pre- and post- high flow images side by side. The pre-flow image is on the left with the post-flow image on the right. The river miles are based on river miles posted on the GCMRC web site. The Lees Ferry area (Figure 3) shows nearly all the various features found along the river bottom.

The reflectivity of bedrock exposures is dark to black, typically exhibiting discernable parallel bedding planes (Figure 4). In many reaches, bedrock is partially overlain by boulders, cobbles, pebbles, or sand (Figure 5).

Boulders (grain diameter $>256 \mathrm{~mm}$ ) appear as large discontinuous features in talus and debris fans. The smallest boulders are comparable in size to a single sonar pixel and are perhaps to small to be resolved clearly, but larger boulders can be resolved individually (Figure 5). Larger boulders commonly have a "sonar shadow" (white area) behind them due to the rock deterring any imaging beyond the rock reflector.

Boulders may look like layered bedrock where boulders become distorted in linear bands as a result of current-induced heave and yaw of the side-scan sonar tow fish, a change in boat speed, or a combination of both (Figure 6). Bedrock and boulders can be distinguished in undistorted images, because boulders and cobbles appear as individual objects, whereas bedding planes in the bedrock are clearly exposed as continuous features (Figure 6).

Sand (diameter between 0.625 and $2.0 \mathrm{~mm}$ ), pebbles (diameter between 2 and $64 \mathrm{~mm}$ ), and cobbles (diameter between 64 and $256 \mathrm{~mm}$ ) are smaller than the sonar pixels and therefore cannot be resolved individually. In the sonar images, sand appears as very nearly white or grey in color (Figures 3, 6, and 7). Sand often occurs as sub-aqueous dunes, with pebbles or cobbles exposed in the dune troughs (Figure. 5).

Dunes up to $40 \mathrm{~m}$ in wavelength and $1 \mathrm{~m}$ in height were found in reaches that contained large amounts of sand (Figures 3, 6, and 7). In underwater video surveys (Anima, et. al., 1998), small-scale ripples are often observed superimposed on dunes, but such ripples are too small to be resolved by the sonar system used in this work.

Pebbles and cobbles have stronger acoustic reflections than sand and therefore appear darker (Figure 7). In some cases, pebbles and cobbles have a mottled texture, perhaps due to spatial variations in grain size, topography, or the presence of sand patches partially covering the coarser bed material. Some dunes have a dark reflectance suggesting that they are composed of pebbles. Underwater video also shows that some dunes are composed of gravel, confirming that dune morphology is not sufficient to identify a sand bed. Pebbles are widespread and are the predominant bed type in some reaches of the river. Pebbles and cobbles are the predominant feature along the tail waters section of the river above Lees Ferry.

\section{Changes in bed material}

The September 2000 LSSF experiment caused the bed material to change at some sites. We observed a number of such changes including: areas where a fine-grained veneer of sand was removed; large areas of change from sand to pebbles and cobles; and areas of change from pebbles and cobbles to sand; and changes in dune size (fig. $8 \& 9$ ). Figures $8 \& 9$ show examples of changes observed along the riverbed and can be seen along most segments of the river. 


\section{Conclusions}

Side-scan sonar gave us the ability to cover a very large area of the riverbed very quickly. The images show very good resolution, and bed features can be identified from survey to survey. Navigation using GPS was adequate for most of the canyon survey, but glitches in the navigation data did occur. With thought and planning, GPS coverage could be improved.

The density of the data collected posed a post-processing problem. The time required to process the data into the images reported here was time consuming, and because these were back to back surveys posed an even greater amount of time and work. This data set proves the viability of the system in these extreme conditions. It can be done. Greater time needs to be anticipated and a team of experienced processors needs to be ready to begin the processing in order to get a faster turnaround time.

Because of the extreme heat conditions in the canyon required steps to be taken to keep the electronics needed to complete the surveys cool. This was achieved by building cases that were able to use the cold river water as a cooling medium for the electronics.

Many would argue that the navigation controls were not adequate to determine centimeter scale changes to the bed material. We don't argue this point, however, to attain a quick look at overall changes in bed texture and how the bed changes over tens of river miles, side-scan sonar is a very good tool.

\section{Acknowledgements}

The Grand Canyon Monitoring and Research Center funded this work. Pete Dartnell, Phil Davis, and Dave Rubin (all USGS) reviewed this manuscript. We would like to thank Lars Neimi, Brian Derker, Stuart Reider, Steve Bledsoe, and other river guides for sharing their knowledge and helping with this project. Without them we would likely still be on the rocks at some point along the river. We would also like to thank Michael and Kelly Hamer, and Joseph Rios, for their assistance in the field, and Nenah Board and Yu Xia, for their help in organizing the data.

\section{References}

Anima, R.J., Marlow, M.S., Rubin, D.M., Hogg, D.J., 1998, Comparison of sand distribution between April 1994 and June 1996 along six reaches of the Colorado River in Grand Canyon, Arizona. U.S. Geological Survey Open-File Report \# 98141,33 pages.

Stevens, L., 1983, The Colorado River in Grand Canyon, Red Lake Books, P.O. Box 1315, Flagstaff, AZ. 86002. Third edition, $3^{\text {rd }}$ printing, 1990. Library of Congress Catalog Card Number: 83-61589.

Wilson, 1998, Telephone conversation discussing the methods used during his survey. 


\section{Figures}

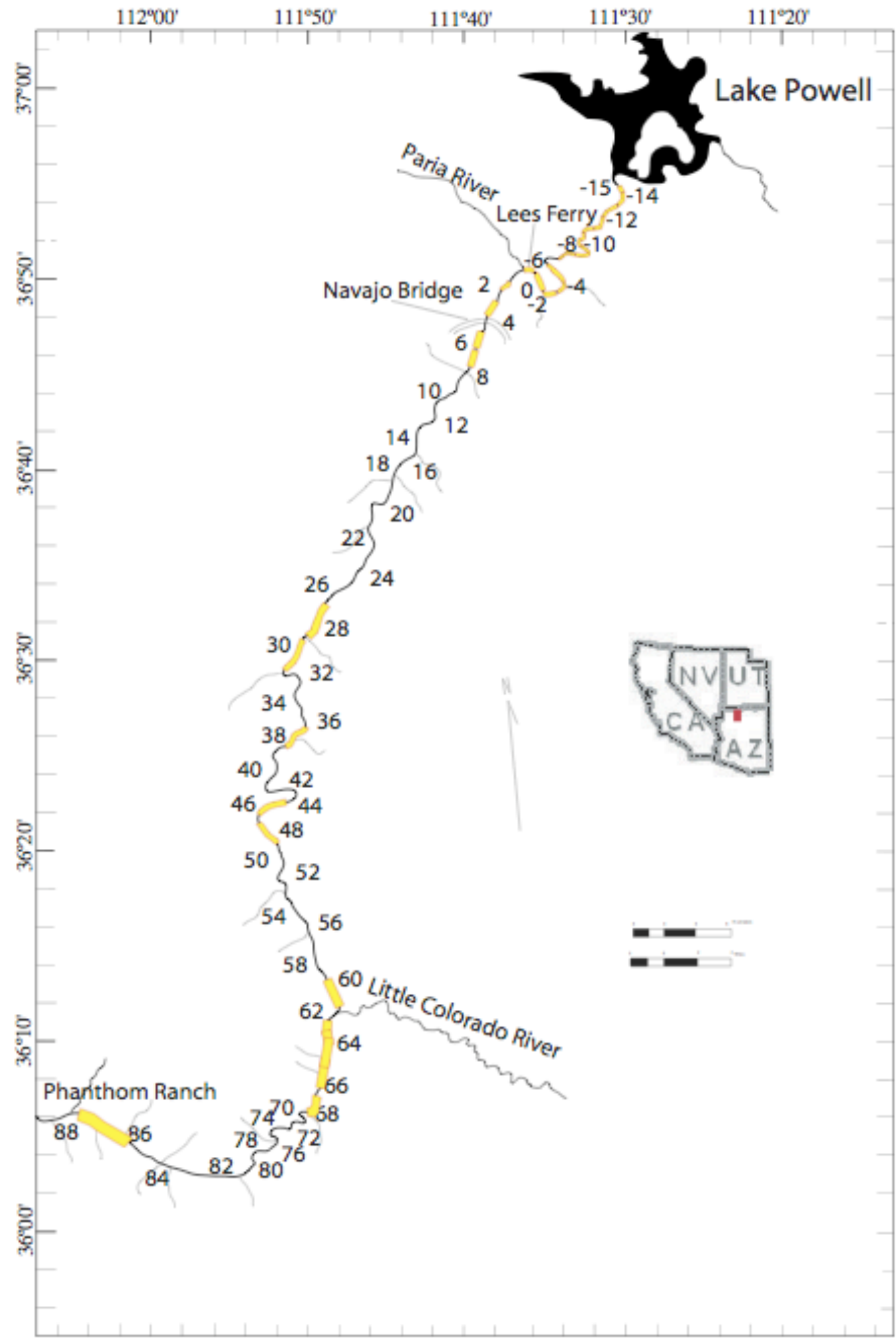

Figure 1. Map showing areas of side-scan sonar coverage between Glen Canyon Dam and river mile 87.5 . 


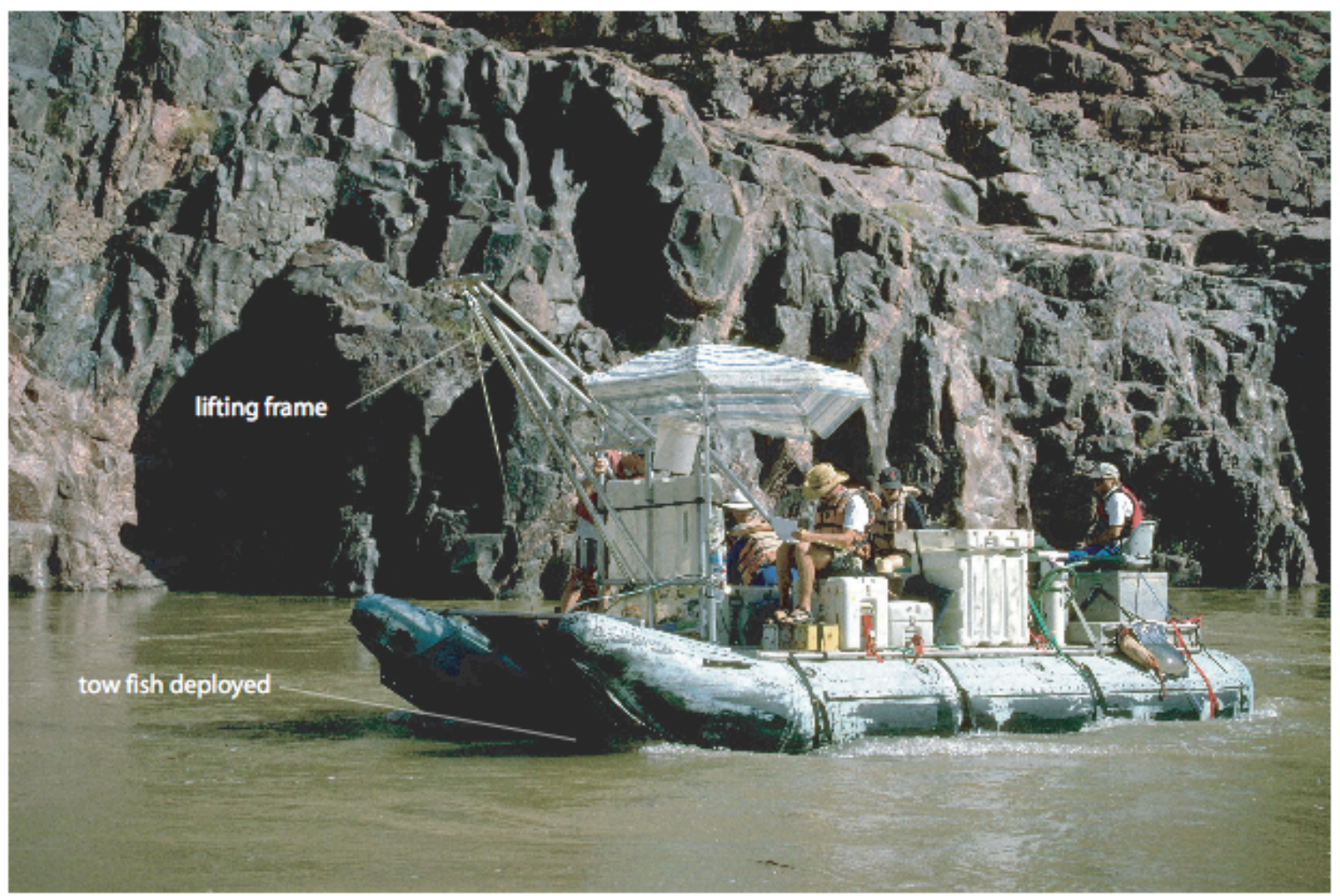

Figure 2. A 22-ft snout rig inflatable boat was used to collect side-scan data. White plastic waterproof boxes housed all electronics. The side-scan tow fish was raised and lowered using the lifting fame at the bow of the vessel.

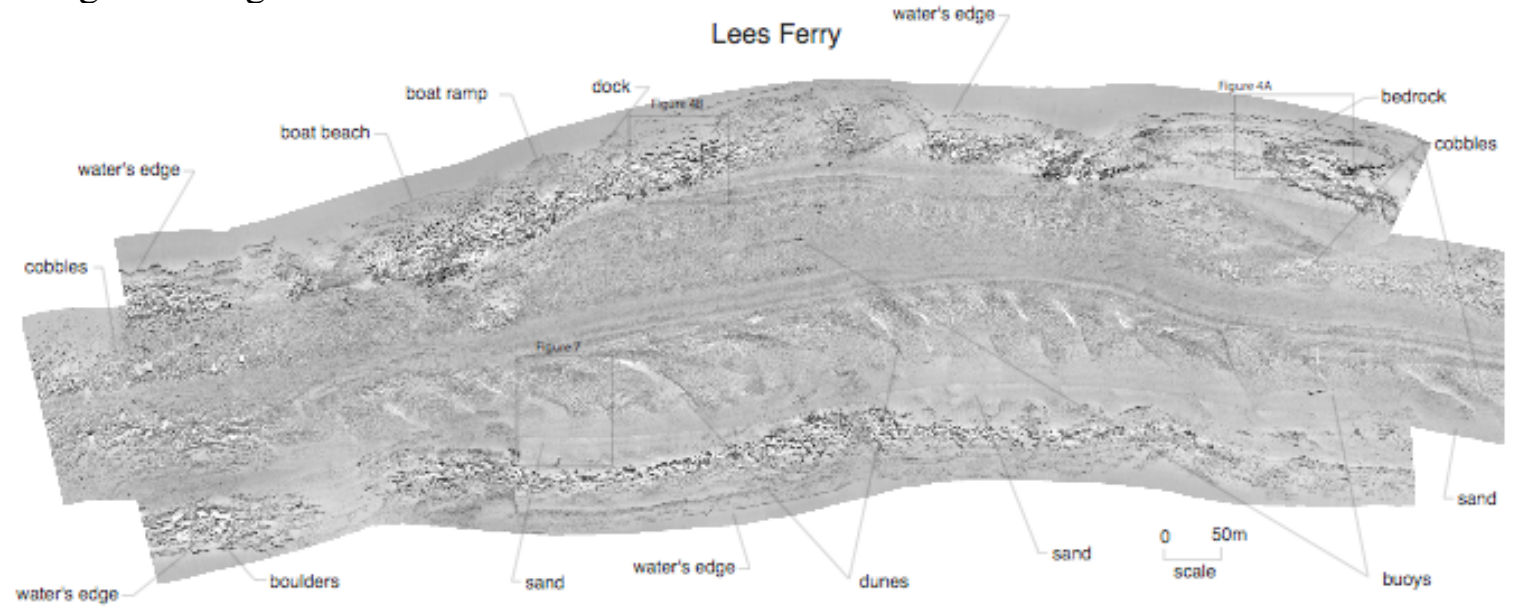

Figure 3. Three side-scan lines were merged to make this mosaic of the Lees Ferry reach (miles 0 to -0.3). Lines were merged using MIPS software. Variations in reflectivity of riverbed features create the differing textural patterns. Refer to Figures 4 and 7 for additional details of each area enclosed in the boxes. 


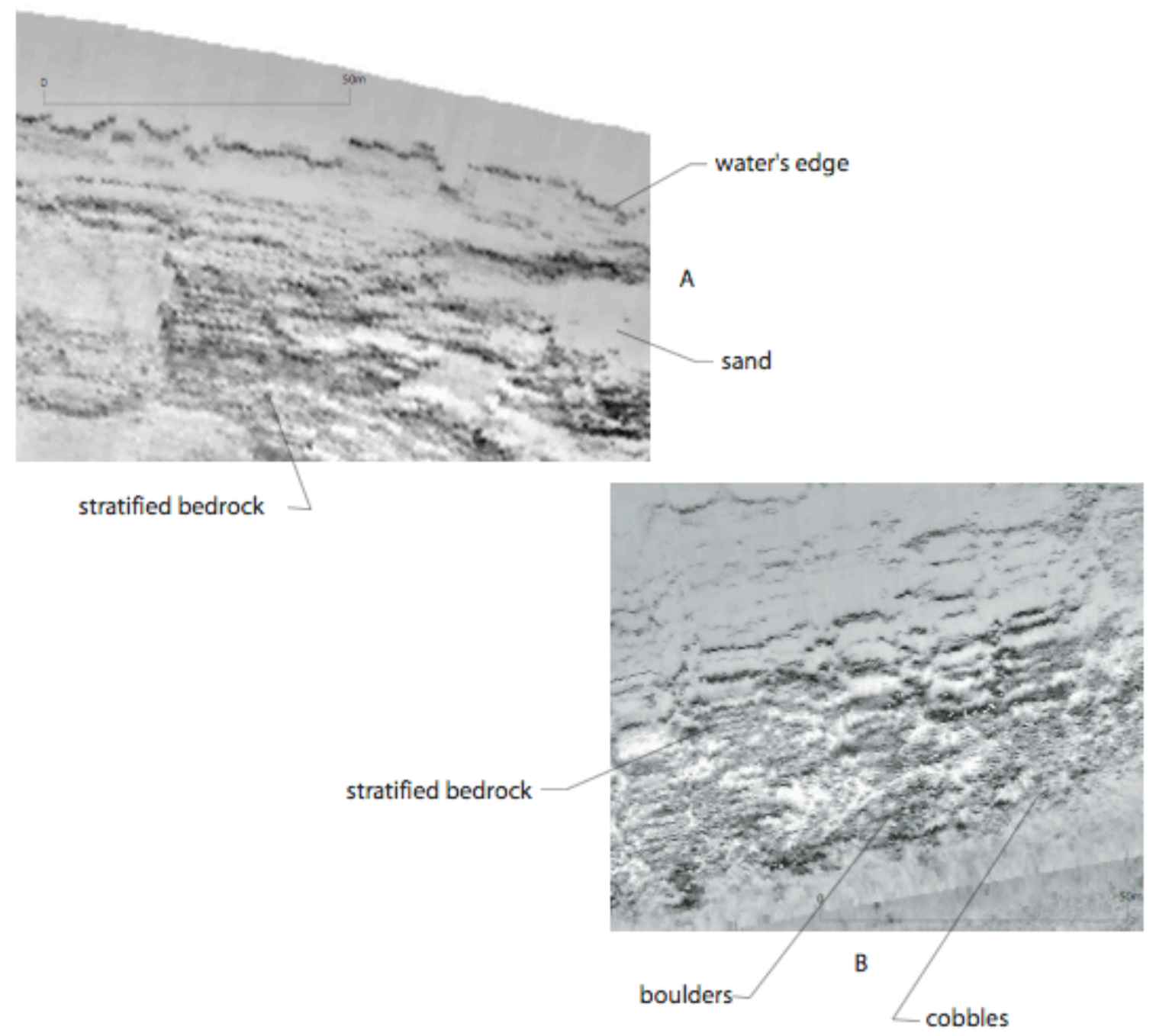

Figure 4. Images of bedrock. A. Bedrock with clear stratification. B. Bedrock partially covered with boulders and other sediment. 


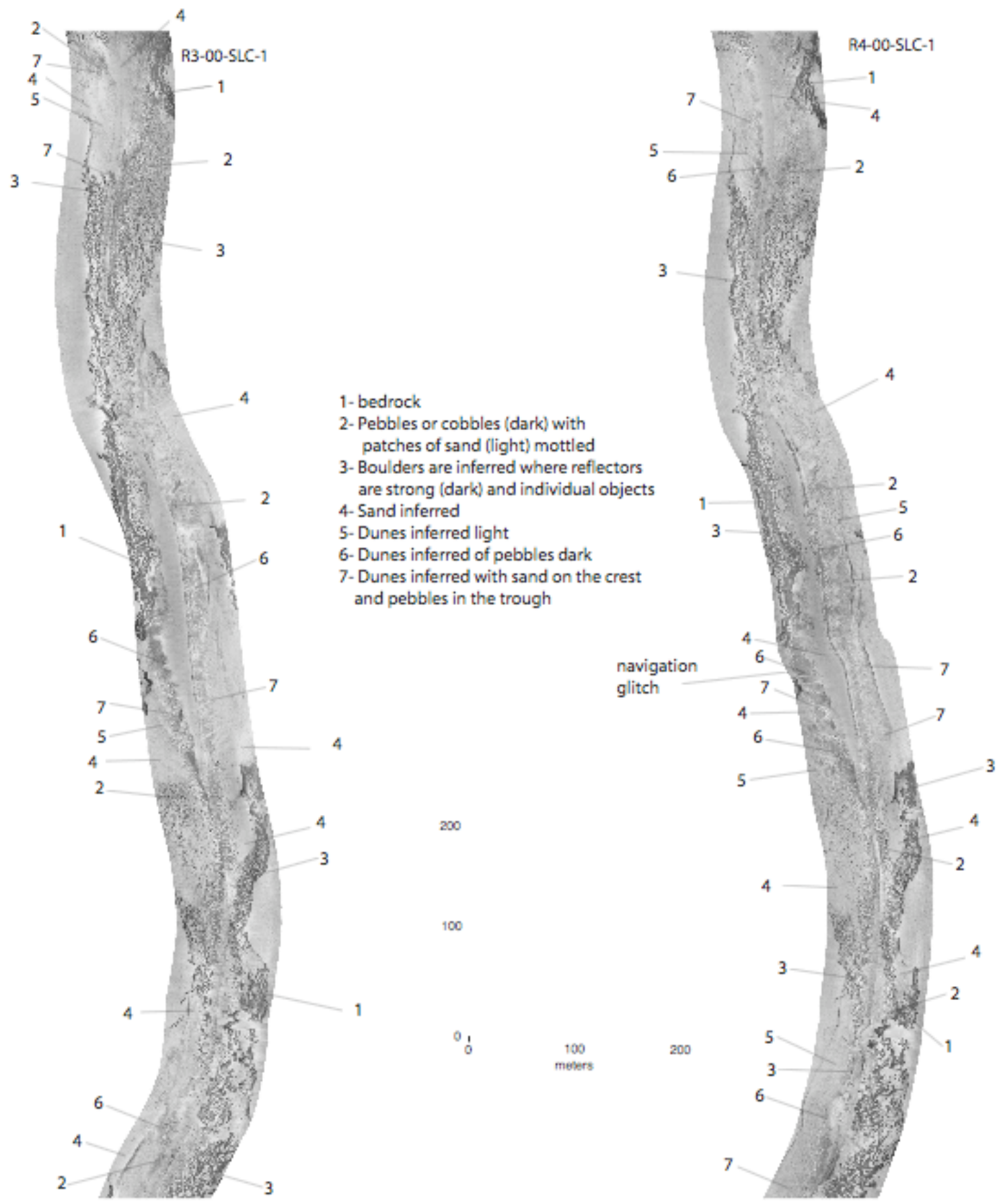

Figure 5. Sections of lines R3-00-SLC-1 and R4-00-SLC1 (between miles 60 and 61). Numbers identify the following bed features: (1) Bedrock with bedding planes is inferred from strong reflections (dark) and parallel continuous structure. (2) Pebbles or cobbles (dark) with patches of sand (light) are inferred to make a mottled pattern. (3) Boulders are inferred where reflectors are strong (dark) and individual objects can be resolved. (4) Sand is inferred where the bed appears light in color and uniformly smooth in texture. (5) Dunes composed of sand are inferred where dunes are relatively light. (6) Dunes composed of pebbles are inferred where dunes are relatively dark. (7) Dunes with sand crests and pebble or cobble troughs are inferred where troughs are dark. 


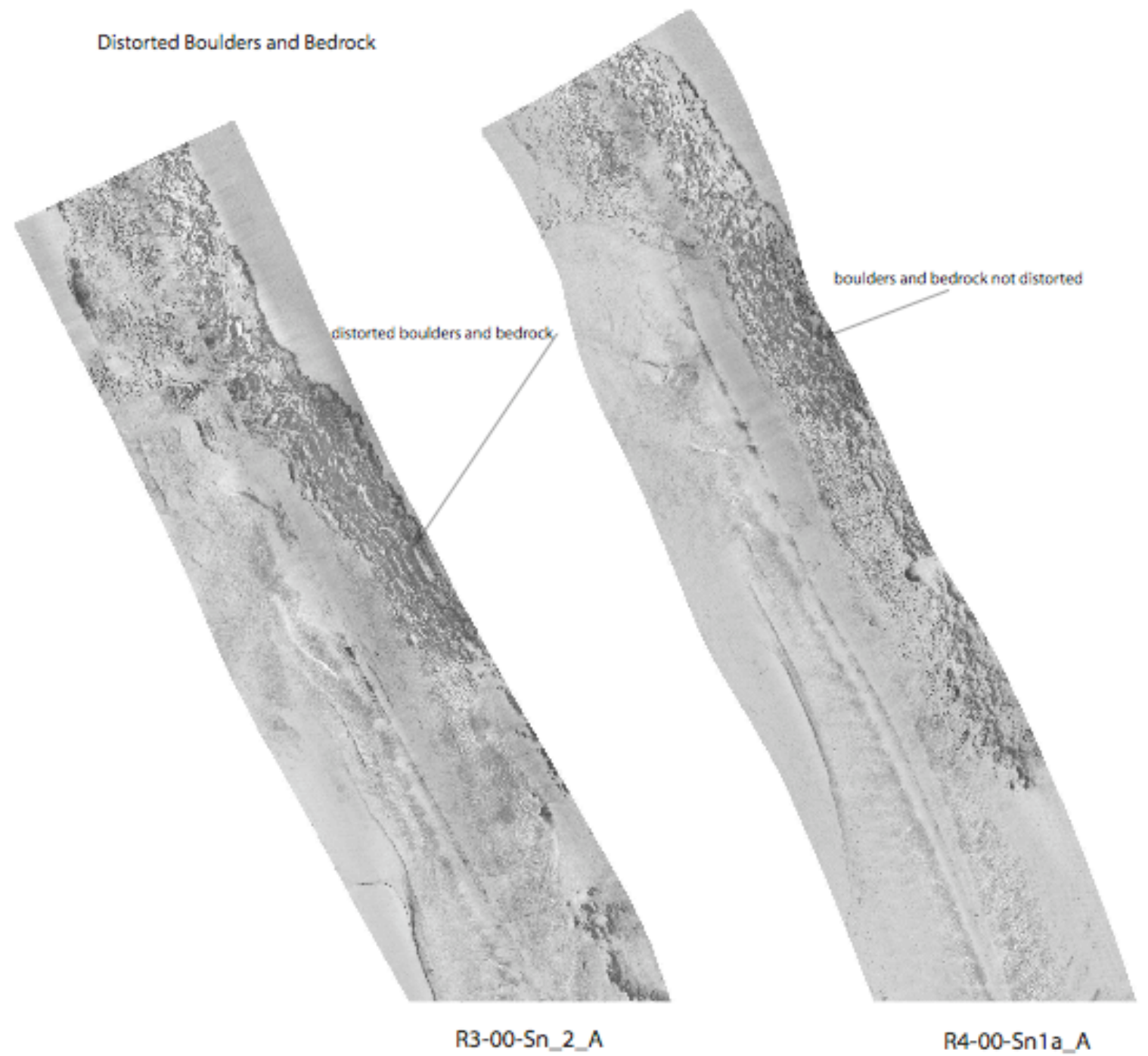

Figure 6. Sections of lines R3-00-Sn_2_A and R4-00-Sn_1_A exhibit examples of an area of distorted boulders and bedrock due to yawing of the side-scan tow fish. 

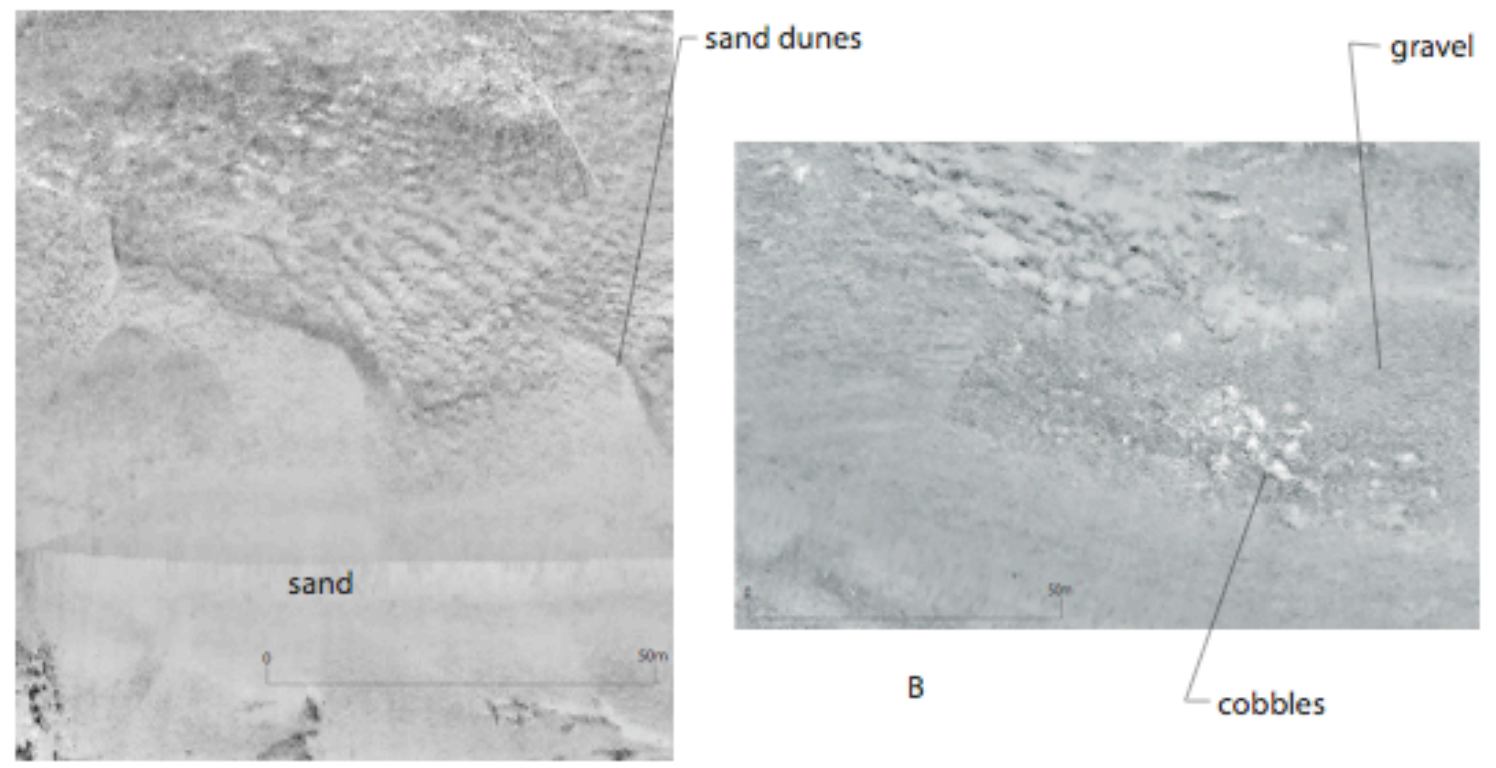

A

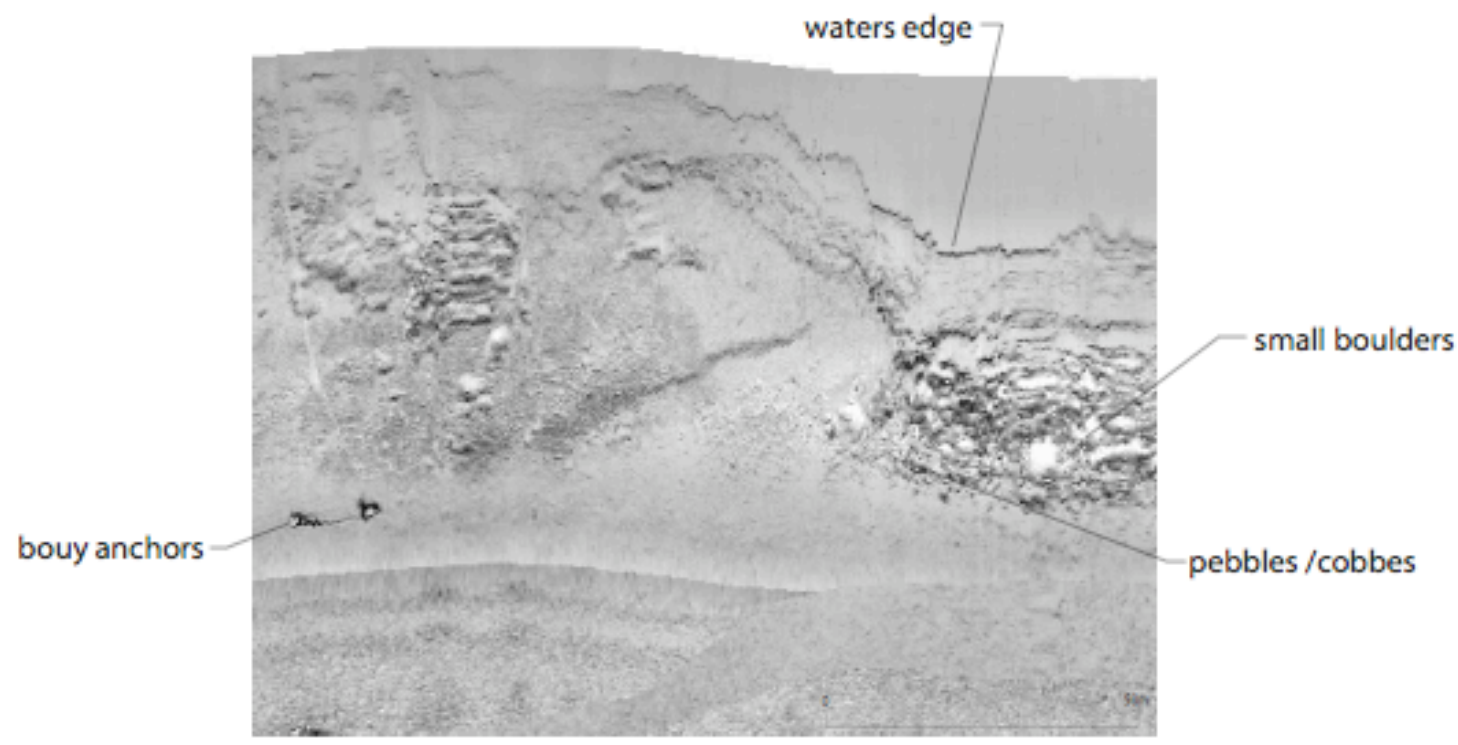

C

Figure 7. Sonar image containing features interpreted as dunes composed of sand, flat or rippled bed of sand, and flat bed of pebbles or cobbles. 


\section{AREAS OF CHANGE IN BED TEXTURE}

AND BEDFORMS

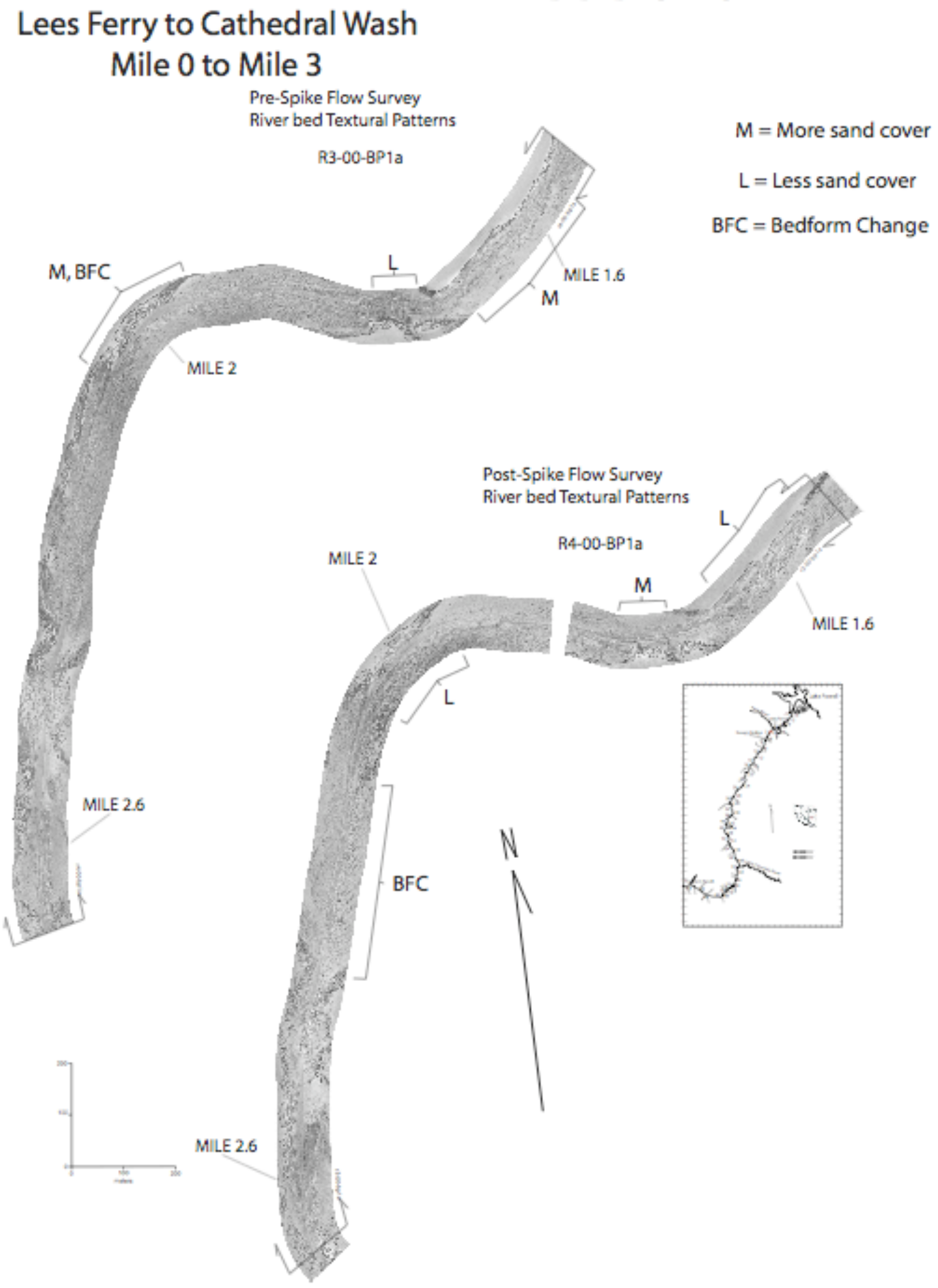

Figure 8. Lees Ferry to Cathedral Wash reaches showing areas of change in bed texture and bedforms in the pre- and post-LSSF. M represents more sand cover; $L$ represents less sand cover; and BFC represents areas of bedform change. 


\section{AREAS OF CHANGE IN BED TEXTURE AND BEDFORMS}

\section{Below Cathedral Wash \\ Mile 3.5 to Mile 4.5}

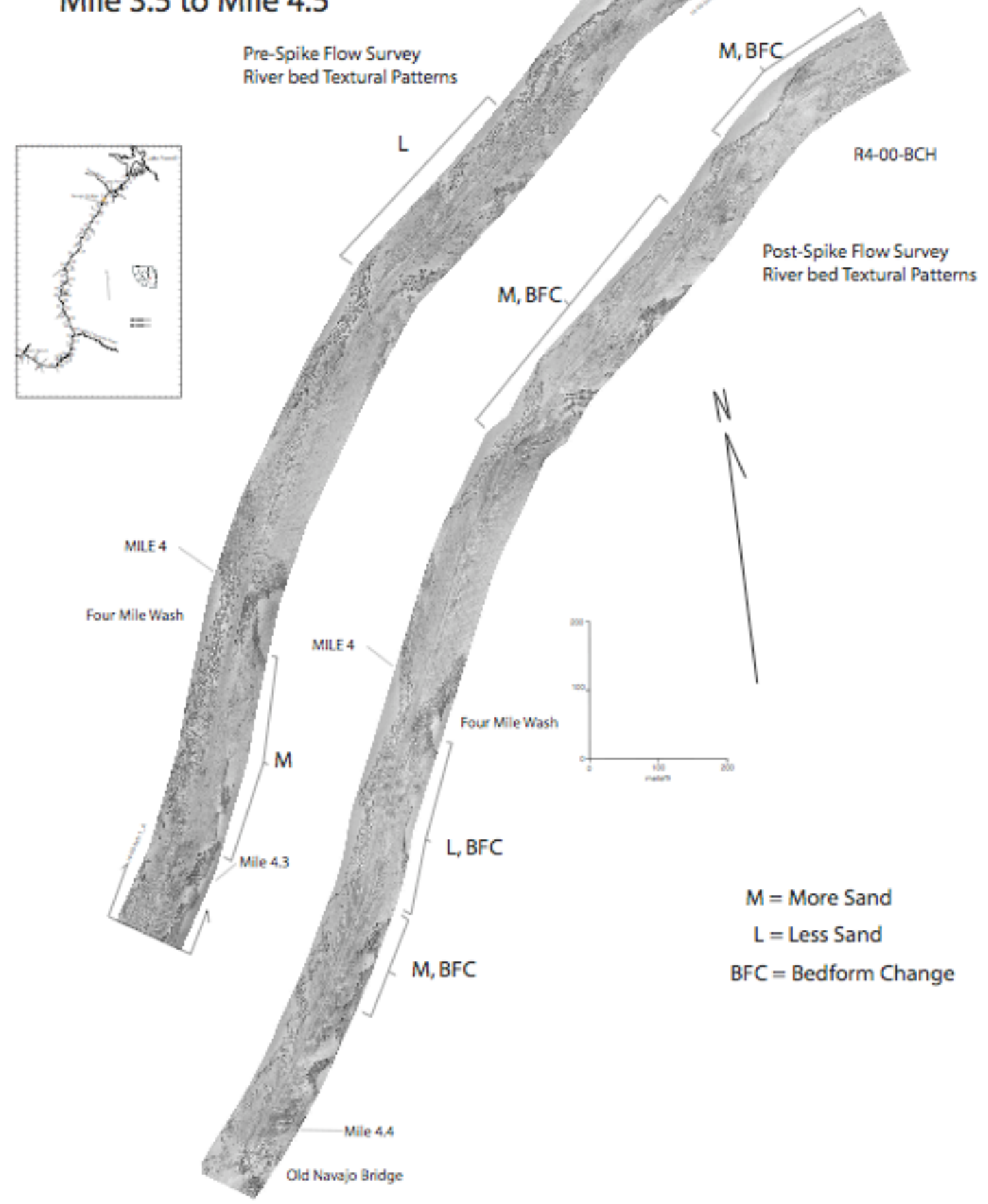

Figure 9. Below Cathedral Wash reaches also showing areas of change in bed texture and bedforms in the pre- and post-LSSF. M represents more sand cover; L represents less sand cover; and BFC represents areas of bedform change. 